\title{
Potential Effectiveness of Poly-Vitamins and Probiotics among Preschool Children Living within Iodine Deficiency Territory to Caries Prevention
}

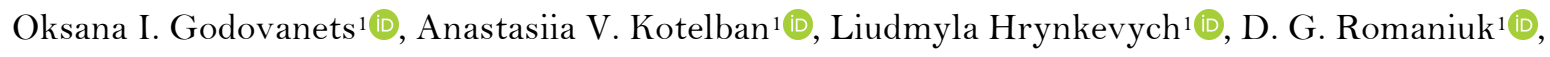 \\ Larisa Ya. Fedoniuk ${ }^{2}$ (]
}

1Department of Pediatric Dentistry, Bukovinian State Medical University, Chernivtsi, Ukraine.

${ }^{2}$ Department of Medical Biology, I. Horbachevsky Ternopil National Medical University, Ternopil, Ukraine.

Correspondence: Oksana Godovanets, Bukovinian State Medical University, Chernivtsi, 58002, Ukraine. E-mail: godovanetspediatricdepartment@gmail.com

Academic Editor: Ana Maria Gondim Valença

Received: 14 July 2020 / Review: 02 September 2020 / Accepted: 29 September 2020

\begin{abstract}
How to cite: Godovanets OI, Kotelban AV, Hrynkevych L, Romaniuk DG, Fedoniuk LY. Potential effectiveness of polyvitamins and probiotics among preschool children living within iodine deficiency territory to caries prevention. Pesqui Bras Odontopediatria Clín Integr. 2021; 21 :e0167. https://doi.org/10.1590/pboci.2021.028
\end{abstract}

\begin{abstract}
Objective: To evaluate the potential effect of poly-vitamins and probiotics use among preschool children permanently living within iodine deficiency territory on caries prevention. Material and Methods: 80 children aged 2-3 years old were randomly distributed among the study group (21 male and 19 females) and control group (20 males and 20 females). Oral fluid samples were formed from each study subject during primary examination and after 1 year of monitoring, which further were analyzed by parameters associated with mineralization potential of oral fluid. Both groups were provided with oral hygiene educational training, while the study group was also prescribed with poly-vitamin-mineral drug complex and probiotics. Results: After 1 year of monitoring, no significant changes considering caries prevalence $(p>0.05)$ or intensity $(p>0.05)$ values were registered among study and control groups. Difference of free calcium level, phosphate ion level and alkaline phosphatase activity was statistically approved $(\mathrm{p}<0.05)$ while comparing between study and control group after 12 months of monitoring. Conclusion: Caries preventive approach consisted of oral hygiene educational training and course of properly prescribed poly-vitamins and probiotics intake demonstrates positive results related to the changes within mineralization potential of oral fluid among preschool children with long-term residence over geographically associated iodine-deficient territory.
\end{abstract}

Keywords: Child, Preschool; Preventive Dentistry; Dental Caries. 


\section{Introduction}

Early childhood caries is an important social and medical problem among all countries globally, representing one of the most prevalent diseases among children population [1,2]. According to the World Health Organization (WHO) information, the frequency and intensity of dental caries among children have declined in several countries; however, in Ukraine, these rates remain high and tend to increase [2-9].

The results of previously provided epidemiological studies in Ukraine demonstrated a high prevalence of deciduous teeth caries, which among children of two years old reached 62.0\%, and among children of three years old - up to $70.3 \%$ [2-4,9-11]. Some regions of Ukraine have shown even greater caries prevalence levels among children, such as $90.95 \pm 2.66 \%$ in Ivano-Frankivsk region, $98 \%$ in Uzhhorod region, from 78 to $93 \%$ in Lviv region, $85.97 \pm 1.90 \%$ in Vinnytsia region [3-11].

High caries prevalence among Ukrainian children argument the need for further development and modification of caries preventive measures, considering the possible influence of regional features on caries spread, such as microelement deficiency conditions over the territory of children's permanent residence [3,4,810,12,13]. Geographically associated microelement deficiency and other environmental parameters have demonstrated a possible impact on children's oral health due to the results of previously published studies $[4,6,8,9,11,14,15]$.

Obtained evidence could not be interpreted as those demonstrating the direct influence of microelements territory-associated levels on the caries-related parameters, but it was found that residents from geographical locations with previously registered calcium, phosphorus, flour or iodine deficiencies in soil and/or water characterized with greater caries intensity and prevalence tendencies $[4,6,8,9,11,14,15]$. Despite that, the possible relationship between caries parameters and territory-associated microelement deficiency or controlled preventive microelement intake should be interpreted with caution, considering the fact of caries definition as biofilm-sugar-disease. At the prophylaxis level, children's oral hygiene education was previously interpreted as a more effective preventive approach compared to the specific microelement substitution in the food or water $[4,5,11]$.

It is well known that dental caries is a multifactorial, diet-associated and bacteriologically provoked disease, manifested by enamel and further dentine demineralization. In general, there are more than 100 risk factors that potentially could be related with dental caries pathology during childhood [4,8-13]. Considering hundreds of variants for such factors' interactions seems logical that caries preventive approaches differ for various children samples while considering the possible influence of the most influential variables. On the other hand, implementing highly effective preventive measures during preschool period could reduce the risk of caries development during further stages of child growth, not only among deciduous but also among permanent dentition.

Recent researches demonstrated the role of oral health education among children of different ages, including preschool ones, with varying effectiveness levels and its strong positive impact on caries prevention $[16,17]$. The effect of probiotics and vitamins combination has been widely discussed in recent studies of different evidence-based levels, especially among children living within territories with registered microelement deficiency conditions [18-21]. Generally, probiotics demonstrate a positive effect on oral health of children and adolescents, restricting possibilities of pathogenic bacteria mass increase, but present clinical data is insufficient to conclude that probiotics intake is definitively cost- and biologically effective specifically for caries prevention and treatment [21]. Also, only a weak type of evidence considering connections between vitamin impact and hard dental tissue lesions is accessible [22]. That is why studies dedicated to the analysis 
of the association between caries parameters and influence of probiotics and vitamins supplements intake, especially among children from areas with established microelement deficiency, could be categorized as relevant and contemporary for present dental science and practice.

Therefore, this study aims to evaluate the potential effect of poly-vitamins and probiotics use among preschool children permanently living within iodine deficiency territory on caries prevention.

\section{Material and Methods}

Study Design and Sample

The sample of preschool aged children was formed out of a number of clinically evaluated children over six childcare facilities in Chernivtsi city (Ukraine). For the inclusion criteria were used: 1) age of children over 6 months (time of first deciduous tooth eruption) till 6 years (time of first permanent tooth eruption); 2) the presence of just deciduous teeth within oral cavity; 3) long-time residence of the child in Chernivtsi (as a city of Subcarpathian region with registered geographically-associated iodine deficiency); 4) absence of allied somathopathology that would restrict child participation in the clinical survey or potentially influence the results of the research; 5) informed consent form signed by child's parents, allowing to provide a clinical examination, additional diagnostic measures and agreement to follow a prescribed protocol of caries prevention. Exclusion of potential participants from study sample was carried out due to the next exclusion criteria: 1) age of children out of 6 month -6 years range; 2) presence of at least one permanent teeth within child's oral cavity; 3) residence within Chernivtsi city or allied peri-urban area for less than 2 years; 4) previous or present drug supplementation considering iodine deficiency conditions over the territory of residence; 5) parents disagreement with informatively provided conditions of the present study without receiving from them signed informed consent form.

Considering the above-mentioned inclusion and exclusion criteria study sample was formed out of 80 persons within the age range of $2-3$ years old (mean age $2.12 \pm 0.37$ years). These 80 children were randomly distributed in two groups using simple randomization with the use of specific randomization software (randomizer.org, where even numbers were used for children allocation to study group, and odd numbers - to control group). In some cases, after provided randomization, but before any clinical investigation, parents refuse to take part in study group, even though they have signed an informed consent form, but agree to move to the control group. Due to the relatively small amount of primary cohort of the patients formed due to the inclusion and exclusion criteria, replacement of participants between study and control groups was provided by the personal will and agreement of parents and children before any clinical examination was started to keep quantity equilibrium between the groups and parallel design of the research. We could interpret the design of the study as quasi-randomized with not fully realized allocation concealment stage. Nevertheless, strictly formed inclusion condition and preservation of quantity equilibrium between the groups supported further research performance. Finally, two groups were formed with 40 children in each: 1) study group (21 male and 19 females); 2) control group (20 males and 20 females).

\section{Data Collection}

Independently of group affiliation during a primary dental examination, each child was evaluated with the assessment of caries intensity parameter (by dmft-index due to the classic methodology) and simplified index of oral hygiene (OHI-S) [23,24]. 
Also, an oral fluid sample $(3 \mathrm{ml})$ was formed from each study subject by spitting method without any stimulation. The procedure was held before breakfast and children mouthwash with plain water 15 minutes before saliva collection, and then wait for another 15 minutes before collection manipulation. After saliva sample was collected into polyethylene tubes, the supernatant was produced by centrifugation due to the algorithm provided for the used diagnostic standard kit (2500 rpm for 10 minutes).

Produced samples were further analyzed on total level of calcium ions (mmol/l), bound calcium level $(\mathrm{mmol} / \mathrm{l})$, free calcium level $(\mathrm{mmol} / \mathrm{l})$, phosphate ion level $(\mathrm{mmol} / \mathrm{l})$, alkaline phosphate activity $(\mathrm{nmol} / \mathrm{s}-\mathrm{l})$ and $\mathrm{pH}$ [25-27]. Those measurements were provided using "Philisit-Diagnostics" diagnostic standard kit (Ukraine) within in-lab conditions by the methodologies (o-cresolphthalein complexone method for calcium level evaluation; phosphoric-molybdic acid recovery method with spectrophotometrical evaluation for phosphate ion level evaluation; immunofluorescent method with Dimension RxL Max Integrated Chemistry System (Siemens Healthineers, Ukraine) for alkaline phosphate activity evaluation; and strip-test for $\mathrm{pH}$ evaluation) already described previously [25-27]. An overall complex of oral fluid examinations was aimed at its' mineralizing potential objectification with further possible interpretation using obtained numerical data. Oral fluid sampling and clinical examination due to above-mentioned methods were carried out at the primary stage of research before any preventive strategy implementation and after 1 year of monitoring. No drop-outs were registered after 12 months of monitoring.

The prevalence of caries was estimated separately for the study and control group of children. All clinical examination procedures and oral fluid sampling were held by two clinical specialists in pediatric dentistry (personal of Department of Pediatric Dentistry at Bukovinian State Medical University), who previously were calibrated and already took part in analogical cross-sectional and epidemiological studies. Reproducibility of examinators considering registration of dmft-index and OHIS-index calculated by Cohen's kappa reached $0.81 \pm 0.06$, while inter-rater percentage agreement was $88.6 \%$.

In both groups, after primary caries- and saliva-associated parameters assessment, each child and his/her parents were trained for basic oral hygiene procedures (use of toothbrush, methodology of tooth brushing, argumentative choice of toothpaste, visual inspection for food debris with its further cleaning) $[16,17,25]$.

Then study group was prescribed with vitamin-mineral drug complex "Supervit" (JSC "Kyiv Vitamin Plant", Ukraine; A11A A04) (1 pill per day during or immediately after a meal, containing vitamins A, D3, E, B1, B2, B6, B12, PP, B5, C, folic acid and microelements $\mathrm{Zn}, \mathrm{Fe}, \mathrm{Cu}, \mathrm{Mg}$, Cr, Se, I in corresponding dosage) and probiotics "BioGaia ProDentis" (BioGaia, Sweden, A07F A 10) (1 pill 2 times per day, containing Lactobacillus reuteri DSM 17938 and Lactobacillus reuteri ATCC PTA 5289 in corresponding amounts) for 20 days due to the drugs prescription's instructions [28,29]. The course of drug intake was repeated 2 times a year with 6 months intervals. The control group was not prescribed any specific drug or supplement, and all preventive measures for this group included only previously provided training for basic oral hygiene procedures.

\section{Data Analysis}

Analysis of obtained data was provided by the blinded principle, due to which end-point researches evaluated just sets of anonymous information without any knowledge of child's correspondence to study or control group. The degree of probability of the obtained results was statistically evaluated in the case of normal distribution within both groups according to the Student-Fisher test; in other cases, U-test for independent samples and Wilcoxon T-test criterion for dependent samples were used. Statistical approving of registered difference reliability between study and control groups by the comparison of the mean values was 
carried out using the Student's t-test. Obtained results were categorized as statistically validated at the significance level of 0.95 with $\mathrm{p}<0.05$. All statistical analysis was provided via Microsoft Excel software (Microsoft Office 2016, Microsoft Corp., USA) with the use of Analyse-it (Analyse-it Software, Ltd., UK) and XLSTAT (Addinsoft Inc., USA) add-ons [30].

Ethical Aspects

The Ethical Committee approved design of provided research of Faculty of Dentistry at Bukovinian State Medical University in 2018. Voluntarily agreement of children themselves and their parents was considered ground base for further analysis of correspondence due to the inclusion and exclusion criteria during study cohort formation.

\section{Results}

Moderate caries prevalence levels were registered among study and control groups, represented by $42.50 \%$ and $45.0 \%$, respectively; difference was not statistically significant ( $>0.05$ ). Analogically caries intensity parameters evaluated by the dmft-index were considered moderate for both groups, reaching dmft $=$ $2.82 \pm 0.28$ in study group and $\mathrm{dmft}=3.01 \pm 0.29 \mathrm{in}$ control group, while difference between them also was not statistically significant ( $\mathrm{p}>0.05)$. OHIS-index parameters revealed a mean of $1.93 \pm 0.11$ points (fair) for study group and a mean of $1.97 \pm 0.10$ points (fair) for control group at baseline, being statistically similar for both groups $(\mathrm{p}>0.05)$.

After 1 year of monitoring, no significant changes considering caries prevalence $(45.0 \%$ and $47.5 \%$ in study and control group respectively; $\mathrm{p}>0.05)$ or intensity $(\mathrm{dmft}=2.95 \pm 0.29$ and $\mathrm{dmft}=3.12 \pm 0.29 \mathrm{in}$ study and control group, respectively, $\mathrm{p}>0.05$ ) values were registered among study and control group, while difference between them due to the above mentioned caries-associated parameters also was not statistically significant $(\mathrm{p}>0.05)$. However, relevant changes occurred within OHIS values, which were improved to $0.92 \pm$ 0.18 (good) and $0.96 \pm 0.27$ (good) after 1 year of monitoring in study and control group, respectively. Such increase was statistically validated $(\mathrm{p}<0.05)$ comparing to the initial situation before the use of poly-vitamins and probiotics or oral hygiene training.

Dynamic changes of parameters associated with the oral fluid's mineralization potential, identified before and after use of poly-vitamins and probiotics, represented in Table 1.

Table 1. Indicators of the parameters associated with mineralization potential of the oral fluid among preschool children.

\begin{tabular}{|c|c|c|c|c|}
\hline \multirow[t]{2}{*}{ Parameters } & \multirow[t]{2}{*}{ Group } & \multicolumn{2}{|c|}{ Use of Poly-Vitamins and Probiotics } & \multirow[b]{2}{*}{ p-value } \\
\hline & & Before & After & \\
\hline \multirow[t]{2}{*}{ Total level of calcium ions $(\mathrm{mmol} / \mathrm{l})$} & Study & $0.93 \pm 0.05$ & $1.45 \pm 0.12$ & $<0.05$ \\
\hline & Control & $0.98 \pm 0.05$ & $1.05 \pm 0.07$ & $>0.05$ \\
\hline \multirow[t]{2}{*}{ Bound calcium (mmol/l) } & Study & $0.51 \pm 0.03$ & $0.59 \pm 0.03$ & $>0.05$ \\
\hline & Control & $0.54 \pm 0.02$ & $0.69 \pm 0.03$ & $>0.05$ \\
\hline \multirow[t]{2}{*}{ Free calcium (mmol/l) } & Study & $0.42 \pm 0.02$ & $0.86 \pm 0.08$ & $<0.05$ \\
\hline & Control & $0.44 \pm 0.03$ & $0.54 \pm 0.08 *$ & $>0.05$ \\
\hline \multirow[t]{2}{*}{ Phosphate ion level (mmol/1) } & Study & $3.55 \pm 0.09$ & $4.23 \pm 0.11$ & $<0.05$ \\
\hline & Control & $3.42 \pm 0.15$ & $3.67 \pm 0.07 *$ & $>0.05$ \\
\hline \multirow[t]{2}{*}{ Alkaline phosphatase activity (nmol/s-l) } & Study & $3.12 \pm 0.20$ & $4.22 \pm 0.15$ & $<0.05$ \\
\hline & Control & $2.98 \pm 0.15$ & $3.07 \pm 0.11^{*}$ & $>0.05$ \\
\hline \multirow[t]{2}{*}{$\mathrm{pH}$} & Study & $6.67 \pm 0.19$ & $7.05 \pm 0.50$ & $<0.05$ \\
\hline & Control & $6.64 \pm 0.19$ & $6.68 \pm 0.24$ & $>0.05$ \\
\hline
\end{tabular}

$\mathrm{p}<0.05$ - the difference of parameters before and after use of poly-vitamins and probiotics is statistically significant; $*$ the difference between the parameters in study and control group after use of poly-vitamins and probiotics is statistically significant $(\mathrm{p}<0.05)$. 
Obtained data demonstrated that changes registered after use of poly-vitamins and probiotics in study group were statistically significant considering total level of calcium ions $(\mathrm{p}<0.05)$, free calcium level $(\mathrm{p}<0.05)$, phosphate ion level $(\mathrm{p}<0.05)$, alkaline phosphatase activity $(\mathrm{p}<0.05)$ and $\mathrm{pH}(\mathrm{p}<0.05)$, while in control group none of these parameters demonstrated relevant changes after 1 year of monitoring. However, while comparing all above-mentioned indicators between the study and control group after 12 months of monitoring, the only difference of free calcium level, phosphate ion level and alkaline phosphatase activity was statistically approved $(\mathrm{p}<0.05)$. Parameters of total calcium level, bound calcium and $\mathrm{pH}$ remained statistically analogical in both groups after 1-year observation ( $\mathrm{p}>0.05)$.

Thus, alkaline phosphatase reactivation with its significant increase on up to $26.06 \pm 3.55 \%$ could be potentially associated with raise of phosphate ions levels (on up to $16.08 \pm 2.60 \%$ ), considering metabolic mechanisms related to both these parameters. Calcium amount gain within oral fluid was predominantly promoted by its free component from $0.42 \pm 0.02 \mathrm{mmol} / 1$ to $0.86 \pm 0.08 \mathrm{mmol} / \mathrm{l}$ on more than $50 \%$ compared to initial situation in study group. These changes certainly had a positive effect on the course of local mineralization processes

Age and gender parameters have shown no statistical inter-relations with caries prevalence $(\mathrm{p}>0.05)$, caries intensity $(\mathrm{p}>0.05)$ or mineralization properties of oral fluid $(\mathrm{p}>0.05)$ changes in study or control group.

\section{Discussion}

Caries pattern within primary dentition of preschool children represents advanced explorative model, composed of different aspects associated with intra-oral conditions and outer environmental influential factors, including climate, geographical, social and family-related variables [4-9]. Parameters of the oral fluid mineralization remain in the role of dynamic indicators that, in combination with dmft-index levels, potentially could be used not only as components for complex caries investigational model, but also for the effectiveness assessment of used treatment or preventive protocol. The role of above-mentioned parameters was represented within provided study, considering specific framework of its realization (territory of residence, age range, use of poly-vitamins and probiotics and targeted measurements), where changes of free calcium level, phosphate ion level and alkaline phosphate activity were characterized with enough statistical significance for proposed use of poly-vitamins and probiotics argumentation. Such fact could also be interpreted as the possibility of those parameters being used as benchmarks for further assessment of other caries preventive algorithms within the primary dentition of preschool children.

Following the STROBE criteria checklist as a part of systematic review design, it was found that seven articles with moderate and low risk of bias demonstrated statistical connections between saliva parameters and dental caries in various forms of inter-relations [31]. In one of the analyzed studies, such connections were represented between a lower person's susceptibility to caries and an increase in saliva calcium, phosphorus, and alkaline phosphatase levels [31]. The present research design did not carry a cariesfree group, but subjects with resulted in stable caries intensity levels were also characterized with raising pattern of phosphate ion and alkaline phosphatase activity levels.

Under the cross-sectional study conditions among children-residents of the Subcarpathian region, authors found that caries intensity levels were more related to the saliva-associated parameters, rather than salivary flow rate [25]. Even though salivary flow rate was not a targeted measurement of present research, we also registered an association between the stabilized pattern of caries intensity and increasing tendency of calcium content within oral fluid. 
Although all studied indicators of oral fluid mineralization potential had shown increasing trend both in study and in control groups, only few of them demonstrated statistically significant differences between groups. Such an outcome could be reached because both studied approaches (poly-vitamins and probiotics in combination with oral hygiene training and oral hygiene training itself) provided a positive effect on all abovementioned oral fluid mineralization potential parameters, but only a few of them characterized with sufficient level of sensitivity and specificity to register inter-group differences considering specific conditions of provided survey. In other words, such parameters are statistically affiliated with potential poly-vitamins and probiotics influence. Such outcome, however, could not be interpreted as a direct caries-preventive effect but rather was related to the optimization of microelement environment within oral fluid. Condition of oral fluid mineralization potential, on the other hand, is a component of caries risk-prognostic model, but connection between exact changes of its' parameters and caries characteristics under the influence of poly-vitamins and probiotics use should be further examined in detail. An analogical situation was described in a previous study, where salivary content parameters were also statistically associated with caries intensity [25].

A systematic review demonstrated that probiotics might be considered as antagonist agents to Streptococci mutans and other cariogenic microorganisms, but direct effect of probiotics on caries lesions development remains under further researches with randomized controlled design [18]. But in a cluster randomized trial, it was established that probiotics incorporated in food increased buffering capacity of saliva (also containing phosphate system) among preschool children [32]. Probiotic group demonstrated a more pronounced effect of caries prevalence decrease, but such, even though in a less express manner, was also registered among control group, thus restricting possibilities of cost-effective argumentative probiotics use for caries prevention [32]. Recent conclusions about caries incidence decrease due to some specific poly-vitamin complex intake could be categorized as low-certainty ones [22]. Although, in our study, we could not differentiate which factor (vitamins, probiotics or their combination with oral hygiene training measures) provided the greatest impact on the increase of mineralization potential of oral fluid, but what more important that such effect was reached, and potentially it could be further used as a component for caries prevention programs among preschool children after further in-depth research. Moreover, there is a need for cost-effective supplemental analysis of poly-vitamins and probiotics use with specific aim of caries prevention. Till the time, when the preventive benefit of such an approach would not be evidently reasoned, it is not argument to implement it practically among preschool facilities or at-home condition. It would be beneficial to promote further research of poly-vitamins and probiotics use as supplements for preventive caries aim (tertiary endpoint), considering isolated role of each of them (secondary end-point), while monitoring and correcting children's diet regarding sugar content as primary end-point of future study.

A survey of preschool children in Hong Kong helped to identify connections between children's caries cases and such parameters as oral health-associated attitude, social-economical environment and parental guidance [33].

In a recent systematic review of randomized trials, it was found that personal hygiene itself is not evidently effective alternative to gain a decreasing effect of dental caries incidence [34]. Inclusion criteria of this systematic review did not have any restrictions considering age. Even though results of such should be interpreted with caution, it is partially consistent with results obtained in the present study. We also have found that training of personal oral hygiene measures among preschool children had a positive impact on mineralization potential of oral fluid, but an increase of oral fluid mineralization potential among control group was far less expressed compare to group, where additional intake of vitamins and probiotics was provided. 
Oral hygiene education combined with vitamins and probiotics intake could also be improved by implementing game-like methodology for such training (lessons). Effectiveness of those already has been approved among preschool children, which helped them adapt to the appropriate tooth brushing [35]. Moreover, another survey demonstrated that parents themselves are not appropriately educated about preschool children's dental hygiene, and more than half of parents-respondents informed about no toothbrushing of their children during 0-3 years old [36]. Also, even though in our study we used OHIS to monitor hygiene level changes among two groups, but such type of indices also could be used by parents themselves to evaluate bacterial plaque load in their children over a specific period, an increase of which could be potentially associated with greater caries risk [37].

Limitations of present study potentially could be related with such two factors, as relatively small size of study and control groups (sample for residents of specific region with persistent iodine deficiency should be statistically representative due to the overall population quantity of specific age group), and also with an inability to provide dynamic monitoring among study subjects, considering not just caries parameters, but also diet specifics and socio-economic status. Further analysis would be dedicated to the prolonged monitoring of oral fluid mineralization values with frequent control of such 4 times per year, augmented by possible seasonal changes, and the need for sugar content in the diet and socio-economic environment screening, as factors potentially associated with caries epidemiology. Sizes of study and control samples of the children were greatly influenced by the used inclusion and exclusion criteria, because such of them as long time residence within a specific territory, voluntarily agreement of children and parents personal agreement approved by informed consent form restricted the possibility to gather a statistically reasonable amount of the participants, which due to the population size of specific age group (near 10000 children) in the city, confidence level of $95 \%$ and $5 \%$ of margin error should reach 370 persons. The absence of statistical differences between some oral fluid mineralization potential parameters could be related directly to the much lower actual sizes of study and control samples. We will expand the amount of primary clinically examined patients and university cooperation with more preschool facilities, which children attend in the age of 0-6 years, to overcome the issue of inadequate sample size for future research. Also, due to caries' nature as biofilm-sugar-dependent disease, the absence of children's diet monitoring is considered a significant limitation, which we will compensate in our future research. Absence of diet monitoring among studied children was associated with pilot type of the research provided by the university study group, while target aim was to find out it is any effect of polyvitamins and probiotics use directly or indirectly related to potential caries preventive outcome within specific iodine deficiency conditions. Such factors as diet content and amount, saliva-associated parameters, caries intensity levels within population and family in general, specifics of oral microbiome and socio-economic status of the family should be considered during future analysis of dental status among preschool children.

Nevertheless, considering that present research originally was provided among preschool children of peculiar territory of residence with persistent iodine deficiency, it could be resumed that usage of vitaminenriched complex and probiotics together with oral hygiene educational training is a more effective approach for oral fluid mineralization potential optimization, which indirectly related with potential positive cariespreventive effect. Particularly, such an approach helped normalize alkaline phosphatase activity and, therefore, provide an increase in phosphate ions. Also, an increase of the enamel's morpho-functional stability could be associated with the promotion of calcium and phosphorus within oral fluid, which supports an adequate supply of hard dental tissue with essential trace elements. 


\section{Conclusion}

Caries preventive approach consisted of oral hygiene educational training and properly prescribed poly-vitamins and probiotics intake. It demonstrates positive results related to the changes in oral fluid's mineralization potential among preschool children with long-term residence over geographically associated iodine-deficient territory. Obtained outcomes revealed that changes of free calcium level, phosphate ion level and alkaline phosphatase activity potentially could raise the mineralization potential of oral fluid, which could have a hypothetical positive impact on further caries prevention. Although further in-depth research should be provided for the argumentation of such a possible connection. Also, effectiveness of such caries preventive approach should be interpreted with caution, since favored impact was registered only regarding specific parameters of oral fluid without considering possible effect of the diet, and by the fact that caries intensity and prevalence progression over 12 months of monitoring wasn't confirmed in the relatively small study sample.

\section{Authors' Contributions

\begin{tabular}{|c|c|c|}
\hline OIG & (iD) https://orcid.org/0000-0002-1889-3893 & $\begin{array}{l}\text { Methodology, Validation, Formal Analysis, Investigation, Writing - Original Draft, Writing - } \\
\text { Review and Editing and Supervision. }\end{array}$ \\
\hline AVK & https://orcid.org/0000-0001-8266-3454 & Conceptualization, Validation, Resources and Data Curation. \\
\hline LH & https://orcid.org/0000-0003-2460-2105 & Methodology, Validation and Formal Analysis. \\
\hline DGR & https://orcid.org/0000-0003-02 18-3931 & Formal Analysis, Investigation, Data Curation and Writing - Original Draft. \\
\hline LYF & https://orcid.org/0000-0003-4910-6888 & Validation, Data Curation and Visualization. \\
\hline
\end{tabular}

\section{Financial Support}

None.

\section{Conflict of Interest}

The authors declare no conflicts of interest.

\section{Data Availability}

The data used to support the findings of this study can be made available upon request to the corresponding author.

\section{References}

[1] Kassebaum NJ, Smith AGC, Bernabé E, Fleming TD, Reynolds AE, Vos T, et al. Global, Regional, and National Prevalence, Incidence, and Disability-Adjusted Life Years for Oral Conditions for 195 Countries, 1990-2015: A Systematic Analysis for the Global Burden of Diseases, Injuries, and Risk Factors. J Dent Res 2017; 96(4):361-3. https://doi.org/10.1177/0022034517693566

[2] Anil S, Anand PS. Early childhood caries: prevalence, risk factors, and prevention. Front Pediatr 2017; 5:157. https://doi.org/10.3389/fped.2017.00157

[3] Cherepiuk O, Stadnyk P. The level of dental care for children in preschool institutions in Ivano-Frankivsk. Ukrainian Dental Almanac 2016; 1(1):87-9.

[4] Klitynska OV, Kostenko YY, Gurando VR. Determination of the criteria of early caries diagnostics in children of different ethnic groups domiciled in areas biogeochemically deficient in fluorine and iodine. J Stomatol 2017; 70(1):516. https://doi.org/10.5604/01.3001.0010.1778

[5] Klitynska OV, Kostenko Y, Mukhina YA, Vasko A, Layosh N. Efficiency estimation of using phased program of caries prevention in children domiciled in Transcarpathian region. Acta Stomatol Naissi 2016; 32(74):1635-49. https://doi.org/10.5937/asnl674635K

[6] Goncharuk-Khomyn MY, Melnychuk NI, Yavuz I, Melnychuk DV. Comparative analysis of the major dental pathologies prevalence among children of transcarpathian region according to the data of the studied clinical sample and preliminary performed dental research. Bull Sci Res 2018; 4:152-6.

https://doi.org/10.11603/2415-8798.2018.4.9802

[7] Tkachenko IM, Brailko NN, Kovalenko VV, Nazarenko ZJ, Sheshukova OV. Morphological study of enamel and dentin teeth with carious process and non-carious lesions. Wiad Lek 2018; 71(5):1002-5. 
[8] Trufanova V, Sheshukova O, Davydenko V, Polishchuk T, Bauman S, Dobroskok V. Characteristics of epidemiology of dental caries in children from regions with high and optimum fluorine content in drinking water. Wiad Lek 2018; $71(2 \mathrm{pt} 2): 335-8$

[9] Sheshukova OV, Trufanova VP, Polishchuk TV, Kazakova KS, Bauman SS, Lyakhova NA, et al. Monitoring of efficiency of dental caries management in children's temporary teeth throughout Poltava oblast. Wiad Lek 2018; 71(3 pt 2):761-7.

[10] Kaskova LF, Mandziuk TB, Ulasevych LP, Kuzniak NB. Physical indices of the oral fluid in children with caries and intact teeth at different age periods. Wiad Lek 2019; 72(5 cz 2):1048-105.

[11] Khomenko L, Ostapko O, Bidenko N, Golubeva I. Influence of environment on oral health status of children in Ukraine. Med Sci Ukraine 2016; 12(1-2):51-8.

[12] Narepekha OT, Dubetska-Hrabous IS. The state of hard tissue of temporary teeth in children from orphanages and boarding-schools. Ukrainian Dent Almanac 2016;1(3):100-3.

[13] Skrīvele S, Care R, Bērziña S, Kneist S, de Moura-Sieber V, de Moura R, et al. Caries and its risk factors in young children in five different countries. Stomatologija 2013; 15(2):39-46.

[14] Dmitriev MO, Gunas IV, Dzevulska IV, Zhulkevych IV. Determination of individual cephalometric characteristics of the occlusal plane in Ukrainian young men and young women withorthognatic bite. Biomed Biosocial Anthropol 2018; 33:5-11. https://doi.org/10.31393/bba33-2018-01

[15] Goncharuk-Khomyn M, Akleyin E, Zhulkevych I, Nahirnyi Y, Brekhlichuk P, Mochalov Y, et al. Correspondence between dental and skeletal maturity parameters among patients with different sagittal relationships at the end of puberty period. J Int Dent Med Res 2020; 13(1):223-8.

[16] Rong WS, Bian JY, Wang WJ, De Wang J. Effectiveness of an oral health education and caries prevention program in kindergartens in China. Community Dent Oral Epidemiol 2003; 31(6):412-6. https://doi.org/10.1046/j.1600-0528.2003.00040.x

[17] Kang BH, Park SN, Sohng KY, Moon JS. Effect of a tooth-brushing education program on oral health of preschool children. J Korean Acad Nurs 2008; 38(6):914-22. https://doi.org/10.4040/jkan.2008.38.6.914

[18] Cagetti MG, Mastroberardino S, Milia E, Cocco F, Lingström P, Campus G. The use of probiotic strains in caries prevention: a systematic review. Nutrients 2013; 5(7):2530-50. https://doi.org/10.3390/nu5072530

[19] Poorni S, Srinivasan MR, Nivedhitha MS. Probiotic Streptococcus strains in caries prevention: a systematic review. J Conserv Dent 2019; 22(2):123-8. https://doi.org/10.4103/JCD.JCD_505_18

[20] Jørgensen MR, Castiblanco G, Twetman S, Keller MK. Prevention of caries with probiotic bacteria during early childhood. Promising but inconsistent findings. Am J Dent 2016; 29(3):127-31.

[21] Seminario-Amez M, López-López J, Estrugo-Devesa A, Ayuso-Montero R, Jané-Salas E. Probiotics and oral health: a systematic review. Med Oral Patol Oral Cir Bucal 2017; 22(3):e282-e288. https://doi.org/10.4317/medoral.21494

[22] Cagetti MG, Wolf TG, Tennert C, Camoni N, Lingström P, Campus G. The role of vitamins in oral health. A systematic review and meta-analysis. Int $\mathrm{J}$ Environ Res Public Health 2020; 17(3):938. https://doi.org/10.3390/ijerph 17030938

[23] Drury TF, Horowitz AM, Ismali AI, Maertens MP, Rozier G, Selwitz RH. Diagnosing and reporting early childhood caries for research purposes. J Public Health Dent 1999; 59(3):192-7.

https://doi.org/10.1111/j.1752-7325.1999.tbo3268.x

[24] Chandran T, Ravindranath NS, Kumari D, Tirupati N, Mithun K, Shilpa M, et al. Oral health education intervention among preschoolers: a randomized controlled trial. Indian J Public Health Res Dev 2019; 10(9):363-8. https://doi.org/10.5958/0976-5506.2019.02453.7

[25] Bilyshchuk L, Keniuk A, Goncharuk-Khomyn M, Yavuz I. Association between saliva quantity and content parameters with caries intensity levels: a cross-sectional study among subcarpathian children. Pesqui Bras Odontopediatria Clín Integr 2019; 19:e5048. https://doi.org/10.4034/pboci.2019.191.121

[26] Omer ZQ, Khoshnaw BA. Evaluation of salivary calcium, phosphorus and alkaline phosphatase level in children (4-6 years) with nursing caries in Erbil City. Zanco J Med Sci 2017; 21(3):1943-52. https://doi.org/10.15218/zjms.2017.055

[27] Vijayaprasad KE, Ravichandra KS, Vasa AA, Suzan S. Relation of salivary calcium, phosphorus and alkaline phosphatase with the incidence of dental caries in children. J Indian Soc Pedod Prev Dent 2010; 28(3):156-61. https://doi.org/10.4103/0970-4388.73789

[28] SuperVit pills. Available from: https://compendium.com.ua/info/170486/supervit/ [Accessed on July 12, 2020].

[29] BioGaia Prodentis lozenges. Available from: https://www.biogaia.com/product/biogaia-prodentis-lozenges/ [Accessed on July 12, 2020].

[30] Hannigan A, Lynch CD. Statistical methodology in oral and dental research: pitfalls and recommendations. J Dent 2013; 41(5):385-92. https://doi.org/10.1016/j.jdent.2013.02.013

[31] Hegde MN, Attavar SH, Shetty N, Hegde ND, Hegde NN. Saliva as a biomarker for dental caries: a systematic review. J Conserv Dent 2019; 22(1):2-6. https://doi.org/10.4103/JCD.JCD_531_18 
[32] Villavicencio J, Villegas LM, Arango MC, Arias S, Triana F. Effects of a food enriched with probiotics on Streptococcus mutans and Lactobacillus spp. salivary counts in preschool children: a cluster randomized trial. J Appl Oral Sci 2018; 26:e20170318. https://doi.org/10.1590/1678-7757-2017-0318

[33] Chu CH, Ho PL, Lo EC. Oral health status and behaviours of preschool children in Hong Kong. BMC Public Health 2012; 12:767. https://doi.org/10.1186/1471-2458-12-767

[34] Hujoel PP, Hujoel MLA, Kotsakis GA. Personal oral hygiene and dental caries: a systematic review of randomised controlled trials. Gerodontology 2018; 35(4):282-9. https://doi.org/10.1111/ger.12331

[35] Sigaud CHS, Santos BR, Costa P, Toriyama ATM. Promoting oral care in the preschool child: effects of a playful learning intervention. Rev Bras Enferm 2017; 7O(3):519-25. https://doi.org/10.1590/0034-7167-2016-0237

[36] Calcagnile F, Pietrunti D, Pranno N, Di Giorgio G, Ottolenghi L, Vozza I. Oral health knowledge in pre-school children: A survey among parents in central Italy. J Clin Exp Dent 2019; 11(4):e327-e333. https://doi.org/10.4317/jced.55378

[37] Corchuelo Ojeda J, Soto L. Evaluation of oral hygiene in pre-school children through bacterial plaque supervision by parents. Rev Fac Odontol Univ Antioq 2014; 25(2):313-24. 